\title{
Mobile Adhoc Network (MANET) Routing Protocols Analytical Study
}

\author{
Sd Salman Ali ${ }^{1}$ Dr.G Manoj Someswar ${ }^{2}$ \\ ${ }^{I}$ Ph.D Scholar in CSED, Pacific Academy of Higher Education and Research University, Udaipur. India. \\ ${ }^{2}$ Principal and Professor in CSED, Anwarul- uloom College of Engineering and Technology, Hyderabad.
} India.

\begin{abstract}
Man being social by nature cannot live in isolation. He feels being in company with other cohumans. So sometimes he wants to connect with himself and most of the other times he wishes to be connected with others at other places through one means or the other. Man's persistent desire to be connected with something, or with somebody at a distance sometimes even across the globe any times has paved a way to the numerous inventions like Radio, Television, Telephone, Mobile, Internet culminating in the wireless networks. The mobile Adhoc Network popularly called in recent times MANET's is a unique development in modern times. It has converted the whole world into a global village for peoples to exchange information and diffuse knowledge. In this paper on "MOBILE ADHOC INETWORKS" the writer makes an attempt to explain MANET's in terms of its definition, characteristics, routing, protocols, dynamic source routing and its characteristics etc.
\end{abstract}

Keywords: Internet, network researchers, topology, traditional routing, protocols, assumption, bandwidth, simulation, quantitative study, emulation, stability criterion, dynamic source routing, mobile computing, internet engineering task force, autonomous system.

\section{Introduction}

The three expressions, "any time", "anywhere" and "any how" are applicable more to Mobile computing in general and to Mobile Adhoc Networks in particular than to any other scientific invention and technological development in recent times in as much as mobile computing is getting vastly expanded since its devices smaller, cheaper and more potent in their functioning are available. The myth of being connected "any time", "anywhere", "anyhow" is now transformed into a reality by blending the mobile devices with wireless communication networks. New applications arise from mobile entities interacting and collaborating towards a common goal with cellular phones widely employed and the mobile internet emerging into the market place, concepts of dynamic wireless networks that do not depend on expensive infrastructure draws attention to the area of adhoc networks. (1)

A Mobile adhoc network helps any mobile device whenever it directly and wirelessly communicate with other devices nearby devoid any fixed infrastructure. A mobile node moves. So the network topology changes dynamically and continually. In the absence of any established infrastructure, the mobile adhoc network forces the node to control the network on its own.

\section{Definition of Mobile Adhoc Network:}

A network which is formed by mobile hosts is called a mobile adhoc network.

The charter of Internet Engineering Task Force (IETF) defines a mobile Adhoc Network (MANET)as "an autonomous system of mobile routers and associated hosts connected by wireless links - the union of which forms an arbitrary graph. The routers are free to move randomly and organize themselves arbitrarily. Such a network may operate in a standalone fashion, or may be connected to the larger internet." (2)

The ultimate goal of MANETS is to provide secure routing of data resources to mobile users at anytime from anywhere. In conjunction with the existing routing protocols, providing security for MANET's give rise to significant challenges and performance opportunities. (3)

\section{Manet Characteristics}

Mobile Adhoc Networks (MANET's) are the latest type of networks which offer unrestricted mobility without any underlying infrastructure. Basically, an adhoc network is a collection of nodes communicating with each other by forming a multi-hop network.

MANET has the characteristics mentioned hereunder.

MANET has dynamic topologies in which nodes freely move arbitrarily. The network topology sometimes changes randomly without any restriction on their distance from other nodes. As a result, the whole 
topology changes unpredictably. Next it gives rise to both directional and non-directional links between the nodes.

The nodes in an adhoc network depend on batteries or other exhaustive means for their energy. The battery depletes due to extra work performed by the node in order to survive the network. So the conservation of energy is an important criterion for design optimization.

Wireless networks have significantly lower capacity than infrastructure networks. Throughout wireless communication is much less because of the effect of the multiple access fading, noise, conditions of interference. As a result, congestion becomes a bottle neck in a bandwidth utilization. (4)

MANET's are generally more prone to physical security threats than wireless networks because the adhoc network is a distributed system and all the security threats relevant to such a system are pretty much present, as a result, there is an increased possibility of eaves dropping, spoofing, masquerading and denial of service type of attacks. (5), (130).

\section{Routing In Manets}

A routing protocol is the mechanism by which user traffic is directed and transported through the network from the source node to the destination node. (6) (115).

\subsection{Objectives Of Routing In Manets:}

- To maximize network performance from the application point of view

- To minimize the cost of network itself in accordance with its capacity

- To avoid delay throughout

- To ensure stability of MANET

\subsection{Four Core Functions Of Manets}

Mobile Adhoc Networks have four core functions as mentioned hereunder.

Path Generation: The generation which generates paths according to the assembled and distributed state information of the network and of the application, assembling and distributing network and user traffic state information is called Path Generation.

Path Selection: The Selection which selects appropriate paths based on network and application state information is called Path Selection.

Data Forwarding: That which forwards data containing user traffic along the select route is called Data Forwarding.

Path Maintenance: That which maintains the path along the selected route is called path maintenance.

The adhoc routing protocol has some other important desirable features such as fast route establishment, multiple routes selection, energy or bandwidth efficiency and fast adaptability to link changes.

All routing systems respond in some way or the other to the changes in network and user traffic State. But routing systems widely change in the types of state changes to which they respond and speed of their response. Routing states can be divided into three categories:

- Static

- Quasi Static

- Dynamic

Further, each of the three basic routing functions may be implemented in three ways mentioned here under:

- Centralized

- Decentralized

- $\quad$ Distributed (7)

\subsection{CATEGORIES OF ROUTING PROTOCOLS:}

The Routing Protocols are classified into 3 categories as mentioned here under: (8) (9) (10)

Flat Routing, Hierarchical Routing, (Location Aware Routing)

FLAT ROUTING: It has two schemes

I) Table-Driven (Proactive) Routing Protocols

II) On-Demand (Reactive) Routing Protocols. $(11,12)$

\subsection{Table - Driven Routing (Global/Proactive) Protocols:}

In Proactive routing Protocols, the routes to all the destinations (or parts of the network) are determined at the beginning and they are maintained by using a periodic route update process. In this protocol each mode maintains the information about the other nodes in the tables, though the number of tables used by different protocols differ. The various proactive routing protocols differ in the way in which they update the routing information in the tables. 


\subsection{Destination Sequenced Distance Vector (DSDV)}

The DSDV algorithm is a modification of Distributed Bellman Ford algorithm which guarantees $100 \mathrm{P}$ free routes. It provides a single path to a destination which is selected using the distance vector shortest path routing algorithm. (13)

Two types of update packets are used in order to reduce the amount of overhead transmitted through the network. These are called "FULL DUMP" and "INCREMENTAL PACKETS".

The FULL DUMP Packet carries all the available routing information while the incremental packet carries only the information changed since the last full dump. The incremental update messages are sent more frequently than the full dump packets. But DS DV still introduces large amounts of over head to the net work due to the requirement of the periodic update messages and the over head grows according to $\mathrm{O}\left(\mathrm{N}^{2}\right)$. Therefore the protocol will not scale in large network since a large portion of the network bandwidth is used in the updating procedures.

\subsection{Wireless Routing Protocol (WRP):}

The Wireless Routing Protocol (WRP) also guarantees loops freedom and it avoids temporary routing loops by using the predecessor information. However, WRP requires each node to maintain four routing tables. It introduces a significant amount of memory overhead at each node as the size of the network increases. Another disadvantage of WRP is that it ensures connectivity through the use of 'hello' messages. These 'hello' messages are exchanged between neighbouring nodes whenever there is no recent packet transmission. This will also consume a significant amount of bandwidth and power as each node is required to stay active at all times. In other words they cannot enter sleep mode to conserve their power. (14)

The tables furnished hereunder explain the basic characteristics and complexity of the two routing Protocols.

Table 1. Basic Characteristics of DSDV and WRP

\begin{tabular}{|c|c|c|c|c|c|c|}
\hline Protocol & $\begin{array}{c}\text { Routing } \\
\text { Structure }\end{array}$ & $\begin{array}{c}\text { Number of } \\
\text { Tables }\end{array}$ & $\begin{array}{c}\text { Frequency } \\
\text { of Updates }\end{array}$ & $\begin{array}{c}\text { Hello } \\
\text { Message }\end{array}$ & $\begin{array}{c}\text { Critical } \\
\text { Nodes }\end{array}$ & $\begin{array}{c}\text { Characteristic } \\
\text { Feature }\end{array}$ \\
\hline DSDV & Flat & 2 & $\begin{array}{c}\text { Periodic and } \\
\text { as Required }\end{array}$ & Yes & No & Loop Free \\
\hline WRP & Flat & 4 & Periodic & Yes & No & $\begin{array}{c}\text { Loop freedom } \\
\text { using } \\
\text { predecessor } \\
\text { information }\end{array}$ \\
\hline
\end{tabular}

Table 2. Complexity Comparison of DSDV and WRP

\begin{tabular}{|c|c|c|c|c|}
\hline Protocol & $\begin{array}{c}\text { Convergence } \\
\text { Time }\end{array}$ & Memory Overhead & Control Overhead & $\begin{array}{c}\text { Advantages/ } \\
\text { Disadvantages }\end{array}$ \\
\hline DSDV & $\begin{array}{c}\text { O(Diameter of } \\
\text { network - 1) }\end{array}$ & $\begin{array}{c}\text { O(Number of Nodes in the } \\
\text { Network) }\end{array}$ & $\begin{array}{c}\text { O(Number of Nodes in } \\
\text { the Network) }\end{array}$ & $\begin{array}{c}\text { Loop free/high } \\
\text { overhead }\end{array}$ \\
\hline WRP & $\begin{array}{c}\text { O(Height of the } \\
\text { Routing Tree) }\end{array}$ & $\begin{array}{c}\text { O(Number of Nodes in } \\
\text { Network) }\end{array}$ & $\begin{array}{c}\text { O(Number of Nodes in } \\
\text { the Network) }\end{array}$ & $\begin{array}{c}\text { Loop } \\
\text { free/memory } \\
\text { overhead }\end{array}$ \\
\hline
\end{tabular}

\subsection{On-Demand Routing (Reactive) Protocols}

In On-Demand Routing (Reactive) Protocols, routes are determined when they are required by the source using a route discovery process. These protocols are designed to reduce the overhead encountered in proactive protocols by maintaining information for active routes only. In other words the routes are determined and maintained for the nodes that are required to send data to a particular destination. Route discovery usually occurs by flooding route request packets through the network. When a node with a route to the destination or the destination itself is reached a route reply is sent back to the source node using link reversal if the route request has travelled through the bi-directional links or by piggy-backing the route in a route reply packet via flooding. So the route discovery overhead will grow by $\mathrm{O}(\mathrm{N}+\mathrm{M})$ whenever link reversal is possible and $\mathrm{O}(2 \mathrm{~N})$ for undirectional links when $\mathrm{N}$ represents the total number of nodes and $\mathrm{M}$ represents the total number of nodes in the localized region.

Reactive Protocols are further classified into two categories.

- Source Routing Protocol

- HOP-by-HOP Routing Protocol

\subsection{Source Routing Protocol}

In source Routing on Demand Protocols, each data packet carries the complete source to destination address. So each intermediate node forwards these packets as per the information kept in the header of each 
packet. In other words the intermediate nodes do not need to maintain up-to-date routing information for each active route in order to forward the packet towards the destination. Besides nodes do not need to maintain neighbors' connectivity through periodic beckoning messages. That in large networks the source routing protocols do not perform will is their major drawback.

\subsection{Hop-by-Hop Routing Protocol:}

In hop-by-hop routing protocol which is also called by the name, Point-to-Point Routing each data packet only carries the destination address and the next hop address. Thus each intermediate node in the path to the destination uses its routing table to forward each data packet towards the destination. Its advantage is that the routes are adaptable to the dynamically changing environment of MANETS since each node can update its routing table when they receive fresher topology information and so forward the data packets over fresher and better routes. The disadvantage of this strategy is that each intermediate node must store and maintain routing information for each active route and each node may require to be aware of their surrounding neighbours through the use of the beaconing messages.

\subsubsection{Dynamic State Routing Protocol (DSR)}

The DSR Protocol requires each packet to carry the full address, every hop in the route, from source to the destination. In other words the protocol will not be very effective in large networks, as the amount of overhead carried in the packet will continue to increase as the network diameter increases. Thus in highly dynamic and large networks the overheard may consume most of the bandwidth. But this protocol has numerous advantages over other routing protocols and in small moderately size networks, possibly up to a few hundred nodes, this protocol performs better. An advantage of DSR is that the nodes can store multiple routes in their route cache. In other words the source node can check its route can check its route cache for a valid route before initiating route discovery. If a valid route is found, there is no need for route discovery. This is very beneficial in network with low mobility in as much as the routes stored in the route cache will be valid for a longer period of time. Another advantages of DSR is that it does not require any periodic becoming or 'hello' message exchanges. Thus nodes can enter sleep node to conserve their power. This also saves a considerable amount of bandwidth in the network $(15,16,17,18)$

\subsubsection{Adhoc on Demand Distance Vector Protocol (AODV)}

The AODV routing Protocol is based on DSDV and DSR algorithm. It uses the periodic beaconing and sequence numbering procedure of DSDV and a similar route discovery procedure as in DSR. But there are two major differences between DSR and AODV. The most distinguishing is that is DSR each packet carries full routing information, where as in AODV the packets carry the destination address. In other words AODV has potentially less routing overheads than DSR. The other difference is that the route replies in DSR carry the address of every node along the route, where as in AODV the route replies only carry the destination IP address and the sequence number. The advantage of AODV is that it is adaptable to highly dynamic networks. But node may experience large delays during route construction and link failure may initiate another route discovery which introduces extra delays and consumes more bandwidth as the State of network increases. $(19,20,21)$

\subsubsection{Temporally Ordered Routing Algorithm (TORA):}

The Temporally Ordered Routing Algorithm (TORA) is a distributed Routing algorithm. It is the one in the family which is referred to as link reversal algorithms. TORA is designed to minimize reaction to topological changes. The key concept in this protocol is that control messages are typically localized to a very small set of nodes. It guarantees that all routes are loop free and typically provides many routes to source or destination pair. It provides only the routing mechanism and depends on Internet MANET ENCAPSULATION PROTOCOL (IMEP) for other underlying functions. Each node has a Quintuple associated with it. It represents

- Logical time of link failure

- The Unique ID of the node that defined the new reference level.

- A reflection indicator bit

- A propagation ordering Parameter

- The Unique ID of the node.

The first three elements collectively represent the reference level. A new reference level is defined each time a node loses its last downstream link due to link failure. (22) 
Table: Basic Characteristics of DSR, AODV and TORA

\begin{tabular}{|c|c|l|c|l|}
\hline Protocol & $\begin{array}{c}\text { Multiple } \\
\text { Routes }\end{array}$ & $\begin{array}{l}\text { Route Metric } \\
\text { Method }\end{array}$ & $\begin{array}{c}\text { Route } \\
\text { Maintained In }\end{array}$ & $\begin{array}{c}\text { Route Reconfiguration } \\
\text { Strategy }\end{array}$ \\
\hline DSR & Yes & $\begin{array}{l}\text { Shortest Path or } \\
\text { next path } \\
\text { available }\end{array}$ & Route Cache & $\begin{array}{l}\text { Erase Route then Source } \\
\text { Notification }\end{array}$ \\
\hline AODV & No & $\begin{array}{l}\text { Freshest and } \\
\text { Shortest Path }\end{array}$ & Route Table & $\begin{array}{l}\text { Erase Route then Source } \\
\text { Notification or Local }\end{array}$ \\
\hline TORA & Yes & $\begin{array}{l}\text { Shortest Path or } \\
\text { next path } \\
\text { available }\end{array}$ & Route Table & $\begin{array}{l}\text { Link reversal and } \\
\text { Route repair }\end{array}$ \\
\hline
\end{tabular}

Table: Complexity Comparison of DSR, AODV and TORA

\begin{tabular}{|c|l|l|l|c|}
\hline Protocol & $\begin{array}{c}\text { Time Complexity for } \\
\text { Route Discovery }\end{array}$ & $\begin{array}{l}\text { Time Complexity for } \\
\text { Route Maintenance }\end{array}$ & \multicolumn{1}{|c|}{ Advantage } & Disadvantage \\
\hline DSR & $\begin{array}{l}\mathrm{O}(2 * \text { Diameter of } \\
\text { Network })\end{array}$ & $\begin{array}{l}\mathrm{O}(2 * \text { Diameter of } \\
\text { Network }\end{array}$ & $\begin{array}{l}\text { Multiple Routes, } \\
\text { Promiscuous } \\
\text { overhearing }\end{array}$ & $\begin{array}{l}\text { Scalability problem } \\
\text { due to source routing } \\
\text { and flooding. }\end{array}$ \\
\hline AODV & $\begin{array}{l}\mathrm{O}(2 * \text { Diameter of } \\
\text { Network })\end{array}$ & $\begin{array}{l}\mathrm{O}(2 * \text { Diameter of } \\
\text { Network })\end{array}$ & $\begin{array}{l}\text { Adaptable to } \\
\text { highly dynamic } \\
\text { topologies. }\end{array}$ & $\begin{array}{l}\text { Scalability Problems } \\
\text { and large Delays. }\end{array}$ \\
\hline TORA & $\begin{array}{l}\mathrm{O}(2 * \text { Diameter of } \\
\text { Network })\end{array}$ & $\begin{array}{l}\mathrm{O}(2 * \text { Diameter of } \\
\text { Network })\end{array}$ & Multiple routes & $\begin{array}{l}\text { Temporary routing } \\
\text { loops. }\end{array}$ \\
\hline
\end{tabular}

\subsubsection{HYBRID PROTOCOLS:}

The PROTOCOLS which combine the basic properties of the two classes of flat routing Protocols into one are called HYBRID PROTOCOLS.

These PROTOCOLS are both reactive and Proactive in nature. Each group will have a number of different routing strategies which employ a flat or a hierarchical routing structure.

Hybrid routing Protocols are new generation Protocols. They are both proactive and reactive in nature. These protocols are designed to increase scalability by allowing nodes with close proximity to work together to form some sort of a backbone to reduce the route discovery overheads. This can be mostly achieved by proactively maintaining routes to nearby nodes and determining routes to far away nodes using a route discovery strategy. Most hybrid Protocols proposed to date are zone based. In other words, the network is partitioned or seen as a number of zones by each node. Other nodes group into trees or clusters.

\subsubsection{ZONE ROUTING PROTOCOL (ZRP):}

The Protocol in which the nodes have a zone and which defines a range in hops that each node is required to maintain network connectivity proactively is called ZONE ROUTING PROTOCOL.

Thus for nodes within the routing zone, routes are immediately available for nodes that lie outside the routing zone, routes are determined on demand that is reactively. It can use any on demand routing protocol to determine a route to the required destination.

Its main advantage is that it can significantly reduce the amount of communication overhead when compared to pure reactive protocols such as DSR by allowing routes to be discovered faster. This is because to determine a route to a node outside the routing zone the routing only has to travel to a node which lies on the boundaries, edge of the routing zone of the required destination. Since the boundary node can complete the route from the source to the destination. In other words, the boundary nodes can complete the route from the source to the destination by sending a reply back to the source with the required routing address. The disadvantage of ZRP is that for large values of routing zone the Protocol can behave like a pure proactive protocol, while for some small values it behaves like a reactive Protocol. (23)

\subsubsection{ZONE-BASED HIERARCHICAL LINK STATE PROTOCOL (ZHLS):}

The Protocol which employs hierarchical structure is called ZHLS routing Protocol.

In this Protocol the network is divided into non-over lapping zones. Each node will have a node ID and a Zone ID which is calculated by a GPS. The hierarchical topology is composed of two levels.

- $\quad$ Node Level Topology

- Zone Level Topology

In ZHLS location management is simplified. This is because no cluster head or location manager is involved to co-ordinate the data transmission. In other words there is no processing over head associated with cluster head or location manager selection when compared to HSR, MM WN and CGSR Protocols. In other words a single 
point of failure and traffic bottlenecks can be avoided. Another advantage of ZHLS is that it will reduce the communication overheads when compared to pure reactive protocols such as DSR and AODV. In ZHLS when a route to a remote destination is required that is when the destination is in another zone, the source node broadcast a zone level location request to all other zones, which generate significantly lower over head when compared to the flooding approach in reactive Protocols. Another advantage of ZHLS is that the routing path is adaptable to the changing topology since only the node ID and the Zone ID of the destination is required for routing. In other words no further location search is required as long as the destination does not migrate to another zone. But in reactive protocols any intermediate link breakage would invalidate the route and may initiate another route discovery procedure.

The disadvantage of ZHLS is that all nodes must have a preprogrammed static zone map in order to function. This may not be possible in application where the geographical boundary of the network is dynamic. But it is highly adaptable to dynamic topologies. It generates far less over head than pure reactive protocols. In other words, it may sale well to large networks.

The tables furnished hereunder will explain the characteristics and the complexity of ZRP and ZHLS.

Table: Complexity Comparison of ZRP and ZHLS

\begin{tabular}{|c|l|l|l|l|}
\hline Protocol & \multicolumn{1}{|c|}{$\begin{array}{c}\text { Time Complexity for } \\
\text { Route Discovery }\end{array}$} & $\begin{array}{c}\text { Communication } \\
\text { Complexity for Route } \\
\text { Discovery }\end{array}$ & Advantage & Disadvantage \\
\hline ZRP & $\begin{array}{l}\text { Intra: O(Periodic Update } \\
\text { Interval) / Inter: } \\
\text { O(2*Diameter of } \\
\text { Network) }\end{array}$ & $\begin{array}{l}\text { O(Number of Nodes in a } \\
\text { zone)/ O(Number of nodes } \\
\text { in the network + Number of } \\
\text { Nodes in the Route Reply } \\
\text { path) }\end{array}$ & $\begin{array}{l}\text { Reduce } \\
\text { Retransmission }\end{array}$ & $\begin{array}{l}\text { Overlapping } \\
\text { Zones }\end{array}$ \\
\hline ZHLS & $\begin{array}{l}\text { Intra: O(Periodic Update } \\
\text { Interval)/ Inter: }\end{array}$ & $\begin{array}{l}\text { O(Number of nodes in the } \\
\text { network / Number of Zones } \\
\text { in the Network)/ O(Number } \\
\text { of nodes in the network }+ \\
\text { Number of Nodes in the } \\
\text { Route Reply path) }\end{array}$ & $\begin{array}{l}\text { Reduction of SPF, } \\
\text { low CO }\end{array}$ & $\begin{array}{l}\text { Static zone map } \\
\text { required }\end{array}$ \\
\hline
\end{tabular}

Figure: Provides a brief outline of the different fat-routing protocols proposed for MANETs

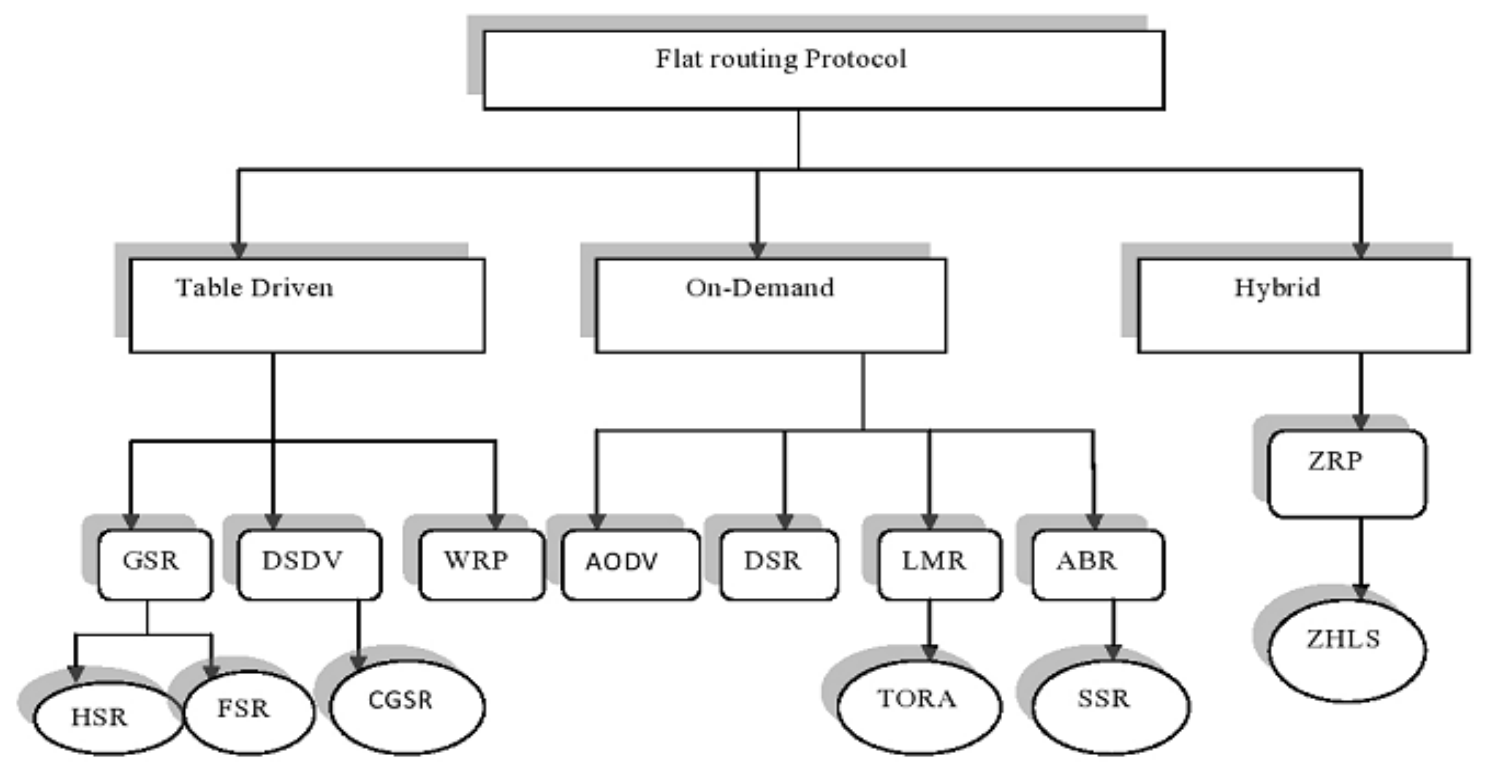




\subsubsection{THE ROUTING PROTOCOLS IN MANETS}

The Geographical Routing Protocols, Power Aware Routing Protocols, Multi-Cast Routing Algorithms are the three other Routing Protocols in MANET's which require brief explanation.

\subsubsection{The Geographical Routing Protocols:}

The Protocols in which the hosts participate in the routing process to be aware of their geographic positions are called the Geographical Routing Protocols.

Adaptive Location Aided Routing Mines - (ALARM)

Distance Routing Effect Algorithm for Mobility - (DREAM)

GPS Ant - Like Routing Algorithm (GPSAL) are the good examples of this kind.

\subsubsection{Power Aware Routing Protocols (PARP):}

The Protocols in which the energy optimization is the main criteria to decide the transmission route is called Power Aware Routing Protocols.

These Protocols take into consideration the energy required to transmit a signal, because the energy required is proportional to the square of the distance and transmitting a signal half the distance requires one fourth of the energy.

- Power Aware Routing Optimization Protocol (PARO)

- Power Aware Multi Access Protocol with Signaling Adhoc Networks (PAMAS) are the good examples of this kind. $(24,25,26,27,28)$

\subsubsection{Multicast Routing Algorithms (MRA):}

The Protocols which are used to address the multi-casting issues are called Multicast Routing Algorithms Protocols.

- On Demand Associativity-Based Multicast Routing Protocol (ABAM)

- Adhoc Multicast Routing Protocol (AM ROUTE)

- Multicast Adhoc on Demand Distance Vector Routing (MAODV) are good examples of this kind.

\section{Network Simulation}

Simulation is defined as imitating or estimating how events might occur in a real situation.

It involves complex mathematical modeling, role playing without the aid of technology, or combinations. The importance of simulation lies in the consideration of realistic conditions that change as a result of behaviour of others involved. Thus we can anticipate the sequence of events or the final outcome. Different simulators such as $\mathrm{ns}_{2}$, Glo Mosim, OPNET are being used by researchers in order to evaluate the routing protocols. We use ns2 for the evaluation of the proposed routing protocol as the same is an open source freely available and the programming languages used are $\mathrm{C}++, \mathrm{Tcl}$ and $\mathrm{OTcl}$.

\section{Conclusion}

In the title of the paper "THE MOBILE ADHOC NETWORK ROUTING PROTOCOLS" three words "ADHOC", "ROUTING" and "PROTOCOLS" demand a detailed critical interpretation in terms of the meaning of each and its application in the present context.

'ADHOC' means that which is made or arranged for a particular purpose.

'ROUTING' means sending something by a specified route.

"PROTOCOL" means a system of rules governing formal occasions.

Thus "MOBILE ADHOC NETWORK ROUTING PROTOCOLS" means 'Network' arranged in Mobile for sending it by a specified route through a system to be used by persons in two or more than two ways for the purpose of Communication.

The popularity of MANETS Routing Protocols is all pervasive throughout the world in recent times in order to make the present world a GLOBAL VILLAGE.

\section{References}

[1]. T. Lin, S.F. Midkiff and J.S. Park "A Framework for Wireless Adhoc Routing Protocols in Proc. Of IEE Wireless Communication and Networking Conference (WCNC) Vol 2. PP $1162-1167-2003$

[2]. A. Boukerche - 'A Simulation based Study of on Demand Routing Protocols lfor adhoc wireless networks. In Proc. $34^{\text {th }}$ Annual simulation symposium PP 85-92 - 2001

[3]. C. Bettstetter and C. Wagner "The Spatial node distribution of the random waypoint mobility model in Proc. Of the $1^{\text {st }}$ German Workshop on Mobile Adhoc Networks, Ulm, Germany Gi Lecture Notes in Informatics No. PP 41-58, 2002

[4]. R.G. Ogier, "Efficient Routing Protocols for Packet-Radio Networks Based on Tree Sharing" in Proc. Of the 6tth IEEE intl. workshop on Mobile Multimedia Communications PP 104-113, 1999

[5]. Vikram Goyal, Shyam K. Gupta, Ananda Gupta. "Malafide Intention and its mapping to Privacy Policy Purposes for Masquerading" in Proc. $10^{\mathrm{th}}$ International Data Base Engineering and Applications Symposium (IDEAS 2006) Pages 311-312, 2006 
[6]. S. Ramanathan and Streen Strup M A Survey of Routing Techniques for Mobile Communication Networks ACM/Baltzer Mobile Networks and Applications, Special issue on Routing in Mobile communication Networks, Vol I No.2 Pages 89 ; 104 - 1996

[7]. C. Murthy and B. Manoj Adhoc Wirless Networks: Architectures and Protocols. Prentice Hall PTR - 2005

[8]. C.E. Perkins - "Adhoc Networking" Addison - Wesley Longman. 2000

[9]. M. Abol Hasan, T. Wysocki and E. Dulkiewicz, "A Review of Routing Protocols for Mobile Adhoc Networks J. Adhoc Networks 2 (2004) PP $1-22$

[10]. Per Johansson, Tony Larsson, Nicklas Hedman, Bartosz Mielczarek and Mikael Degermark, "Routing Protocols for Mobile Adhoc Networks - A Comparative Performance Analysis." IN Proc. Of the Fifth International Conference on Mobile Computing and Networking (Mobi com 99) ACM August 1999

[11]. Robert Castaneda and Samir R.D as "Query Localization Techniques for ON-DEMAND ROUTING PROTOCOLS in ADHOC NETWORKS" in Proc. Of the $5^{\text {th }}$ International Conference on Mobile Computing and Networking (Mobicom 99) ACM August 1999

[12]. Yih-Chunhu and David B. Johnson, "Implicit source Routing in On Demand Adhoc. Network Routing" - in Proc. Of the $2^{\text {nd }}$ Symposium on Mobile Adhoc Networking and Computing Mobi Hoc 2001, Pages 1-10 October 2001

[13]. C.E. Perkinsons and P. Bhagawat "Highly Dynamic Destination - Sequenced Distance Vector Routing (DSDV) for Mobile Compouters". In Proc. Of SIGCOMM 1994.

[14]. Vaduvur Bharghavan, Alan Demers Scott Shenker and Lixia Zhang, MACAW: A Media Access Protocol for Wireless LAN'S. In Proc. Of the SIGCOM' 94 Conference on Communications Architectures Protocols and Applications, Pages 212 - 225

[15]. D.B. Jhonson and D.A. Maltz, "Dynamic Source Routing" in Adhoc Wireless Networks, Mobile Computing. T. Imielinski and H. Korath (Eds.) Chapter 5 PP 153 - 181, Kluwer Academic Publishers, 1996

[16]. D.B. Johnson, D.A. Maltz and J. Broch, "DSR: The Dynamic Source Routing Protocol for Multihop Networks" In Adhoc Netnworking. C.E. Perkins (Ed) Pages 139 - 172, Addison - Wesley - 2001

[17]. David B. Johnson and David A. Maltz, "Dynamic Source Routing in Adhoc Wireless Networks," In Mobile Computing, Imielinski and Korth (Eds) Chapter 5 Pages 153 - 181 Kluwer Academic Publishers, 1996

[18]. Vangelis Angelakis Apostolos, "Extending the Dynamic Source Routing (DSR) Protocol to Deal with Node selfishness in Adhoc Networks.

[19]. http://www.ics.forth.gr/angelak/files/angelaktragani_dsr_selfishness.pdf,

[20]. C.E. Perkins and E.M. Royer, The Adhoc on Demand Distance Vector Protocol (AODV), "In Adhoc Networking C.E. Perkins (Ed.) Pages 173 - 219 Addison - Wesley, 2001.

[21]. C. Perkins “Adhoc on Demand Distance Vector AODV Routing” Internet Draft, draft-ietf-aodv_oo.txt

[22]. Charles e. Perkins AND Elizabeth M. Royer, "Adhoc on Demand Distance Vector Routing" In Proc. $2^{\text {nd }}$ IEEE workshop on Mobile Computing Systems and Applications, Pages 90 - 100, IEEE Computer Society, February 1999.

[23]. V.Park and S. Carson, "Temporally ordered Routing Algorithms (TORA) Ver. I Functional Specification" IFTF draft 2001.

[24]. Zygmunt J. Haas and Marc R. Pearl man, "The Performance of Query Control Schemes for the Zone Routing Protocol". In Proc. Of the ACM SIGCOMM '98 Conference, Pages 167 - 177 September 1998.

[25]. Ashish Gehani, Thomas La Bean and John Reif DNA - Based Cryptography "In Proc 5" DIMACS Workshop on DNA Based Computers, MIT Cambridge, 1999.

[26]. Young-Baeko and Nitin Vaidya, "Location Aided Routing (LAR) in Mobile Adhoc Networks" In Proc. $4^{\text {th }}$ International Conference on Mobile Computing and Networking (Mobicom '98) Pages 66-75, ACM, October 1998.

[27]. Ivan Stojme novice and Xu Lin, "Power Aware Localized Routing in Wireless Networks," IEEE Transactions on Parallel and Distributed Systems, Vol 12 No. 11 Pages 122 - 133 Nov. 2001.

[28]. P.J. Wan, G. Calinescu, X, Y Li, and O. Frieder, Minimum energy broad Cast Routing in Static Adhoc Wireless Networks In Proc. Of the IEEE Conference on Computer Communications (INFOCOM) Pages 1162 - 1171 - 2001.

[29]. Rohit Dube, Cynthia D. Rais, Koang Yeh Wang, and Satish K. Tripathi, "Signal Stability - Based Adptive Routing (SSA) for Adhoc Mobile Networks" IEEE Personal Communications, 4 (1) Pages 36 - 45 Feb. 1997. 